\title{
Tourism informing conservation: The distribution of four dolphin species varies with calf presence and increases their vulnerability to vessel traffic in the fourisland region of Maui, Hawai' $i$
}

\author{
Self, Holly; Stack, Stephanie H.; Currie, Jens J.; Lusseau, David
}

Published in:

Ecological Solutions and Evidence

Link to article, DOI:

$10.1002 / 2688-8319.12065$

Publication date:

2021

Document Version

Publisher's PDF, also known as Version of record

Link back to DTU Orbit

Citation (APA):

Self, H., Stack, S. H., Currie, J. J., \& Lusseau, D. (2021). Tourism informing conservation: The distribution of four dolphin species varies with calf presence and increases their vulnerability to vessel traffic in the fourisland region of Maui, Hawai'i. Ecological Solutions and Evidence, 2(2), [e12065]. https://doi.org/10.1002/2688-8319.12065

\section{General rights}

Copyright and moral rights for the publications made accessible in the public portal are retained by the authors and/or other copyright owners and it is a condition of accessing publications that users recognise and abide by the legal requirements associated with these rights.

- Users may download and print one copy of any publication from the public portal for the purpose of private study or research.

- You may not further distribute the material or use it for any profit-making activity or commercial gain

- You may freely distribute the URL identifying the publication in the public portal 


\title{
Tourism informing conservation: The distribution of four dolphin species varies with calf presence and increases their vulnerability to vessel traffic in the four-island region of Maui, Hawai'i
}

\author{
Holly Self $^{1}$ | Stephanie H. Stack ${ }^{2}$ | Jens J.Currie ${ }^{2}$ | David Lusseau ${ }^{1,3}$ (1)
}

${ }^{1}$ School of Biological Sciences, University of Aberdeen, Aberdeen AB24 2TZ, UK

2 Pacific Whale Foundation, Wailuku, Hawaii, USA

${ }^{3}$ National Institute of Aquatic Resources, Technical University of Denmark, Kgs. Lyngby 2800, Denmark

\section{Correspondence}

David Lusseau, National Institute of Aquatic Resources, Technical University of Denmark, Kgs. Lyngby, 2800, Denmark.

Email:davlu@dtu.dk

Handling Editor: Mark O'Connell

\section{Abstract}

1. We need reliable information about the spatial and temporal distribution of mobile species to effectively manage anthropogenic impacts to which they are exposed. Yet, we often cannot sustain dedicated annual surveys and data obtained from platforms of opportunity offer an alternative avenue to understand where these species spend time.

2. Four odontocete species that occur in the four-island region of Maui, Hawai'i, USA, are vulnerable to a range of human activities, but there is a lack of information regarding their distribution. We therefore do not know the extent of the risk these activities present for the conservation of these species (bottlenose dolphins, spinner dolphins, Pantropical spotted dolphins and false killer whales).

3. We used a cross-validated maximum entropy (MaxEnt) occupancy model to estimate the distribution of these four species in an area extensively observed from platforms of opportunity (PoP). We then determined in a similar fashion whether the calves of those species were more likely to be observed in particular areas and whether distribution changed with season.

4. Maxent models relying on local environmental variables described dolphin observations well (AUC > 0.7). Their distribution differed for all species when calves were present, indicating that different environmental variables describe area use for schools with calves present.

5. The number of sighting events of all species varied significantly with season. Bottlenose dolphins and false killer whales were more prevalent in winter, while spotted and spinner dolphins were more prevalent in summer.

6. We show that an overlap in the distribution of dolphin schools with calves and vessel traffic in the region could result in collision and chronic stress risks. This suggests a need for specific regulations for mitigating anthropogenic influences, such as acoustic disturbance or chronic energetic disturbance from vessel traffic.

This is an open access article under the terms of the Creative Commons Attribution License, which permits use, distribution and reproduction in any medium, provided 
This elevated risk associated with vessel traffic is likely of conservation concern in this region for the endangered population of false killer whales and for spinner dolphins.

\section{KEYWORDS}

cetaceans, distribution, Hawai'i, Maxent, odontocete, Population Consequences of Disturbances, platform of opportunity, species distribution modelling

\section{1 | INTRODUCTION}

The extent to which anthropogenic impacts can cause conservation risks for highly mobile species depends on the degree of overlap in the distribution of human activities and those species (Pirotta et al., 2018). We therefore need reliable information about the species spatiotemporal distribution to manage these risks. The conservation of populations that are not exposed to direct takes, but instead face chronic exposure to non-lethal disturbances, can be affected by reduced reproductive success (Béchet et al., 2004; Beissinger \& Peery, 2007; Crooks, 2002; Manlik, 2019; Manlik et al., 2016; Pirotta et al., 2018; Raithel et al., 2007). Habitat selection may facilitate reproductive success by offering better prey availability, protection from predators or reduction of energy expenditure by providing a more sheltered environment (zu Ermgassen et al., 2016). For species facing chronic exposure to anthropogenic impacts, it is important to understand not only the extent of the overlap between their range and these human activities, but particularly whether there is an overlap with areas where mothers and calves are more likely to be present. Areas known to have high occurrences of juveniles or that function as nursery areas are high priority for conservation efforts and protections (CBD, 2008; IUCN Marine Mammal Protected Areas Task Force, 2018).

The Hawaiian Islands are a marine ecoregion of global importance (Olson \& Dinerstein, 2002). Eighteen odontocete species have been documented in this region, all of which are vulnerable to anthropogenic activities that have the potential to negatively impact population trends. These include fisheries interactions, collision and disturbance risks associated with commercial or recreational vessel traffic (Baird et al., 2013). While many of these 18 species move through the Maui four-island region, there is evidence that three of the dolphins in Hawai'i have island-associated populations, with little documented mixing with other island populations (Carretta et al., 2020). In the Maui four-island region, the most commonly sighted dolphins are (i) the pantropical spotted dolphin, Stenella attenuata (NOAA, 2017c), (ii) the spinner dolphin, Stenella longirostris longirostris (NOAA, 2018), (iii) the bottlenose dolphin, Tursiops truncatus (NOAA, 2017a), and (iv) the false killer whale, Pseudorca crassidens (NOAA, 2013). For all four species, we currently lack detailed information about distribution necessary to manage their conservation threats (Baird et al., 2013; Carretta et al., 2020).
While this region is considered data deficient for some species, it is rich in commercial and recreational vessels that can be used to collect opportunistic data about the location of marine wildlife (Currie et al., 2018). These 'platforms of opportunity' (PoP) can provide an alternative way of obtaining data when costly dedicated survey effort is not feasible (Currie et al., 2018; Kiszka et al., 2007; Moura et al., 2012 ; Williams et al., 2018).

Advances in modelling approaches that can help infer species occupancy using presence-only observations (Elith et al., 2006; Oppel et al., 2012; Phillips, 2009), means that PoP data (Williams, Hedley, \& Hammond, 2018), and indeed other community science data (Currie, Stack, \& Kaufman, 2018), can successfully be used to describe the distribution of wildlife (van Strien et al., 2013).

Here we used environmental variables to describe opportunistic observations of the four dolphin species commonly found within Maui four -island region. This was conducted using data obtained from tour operating vessels in the Maui four-island region and analysis conducted using maximum entropy models to estimate their distribution in this area. Given that the identified conservation threats varied between age classes (Carrillo \& Ritter, 2010; Pirotta et al., 2018), we assessed whether schools observed with calves differed in their distribution from schools without calves. We then assessed the spatial association between dolphin distribution and vessel traffic to determine whether there is significant overlap which could cause conservation concerns.

\section{MATERIALS AND METHODS}

\section{1 | Study area}

The islands of Maui County; Maui, Lana'i, Moloka'i and Kaho'olawe, hereafter referred to as 'the Maui four-island region' lie within the Hawaiian Islands Humpback Whale National Marine Sanctuary $(\mathrm{HIH}-$ WNMS). The study area was determined by the extent of the spatial data available and covers an area of $1890 \mathrm{~km}^{2}$ of the contingent shelf region between the four islands (Figure 1). The deepest region of the study area is the southern section of the 'Alalākeiki channel, which reaches $325 \mathrm{~m}$, while the mean depth of the study area is $54 \mathrm{~m}$. Anthropogenic activity in the region is high, with a large quantity of vessel 


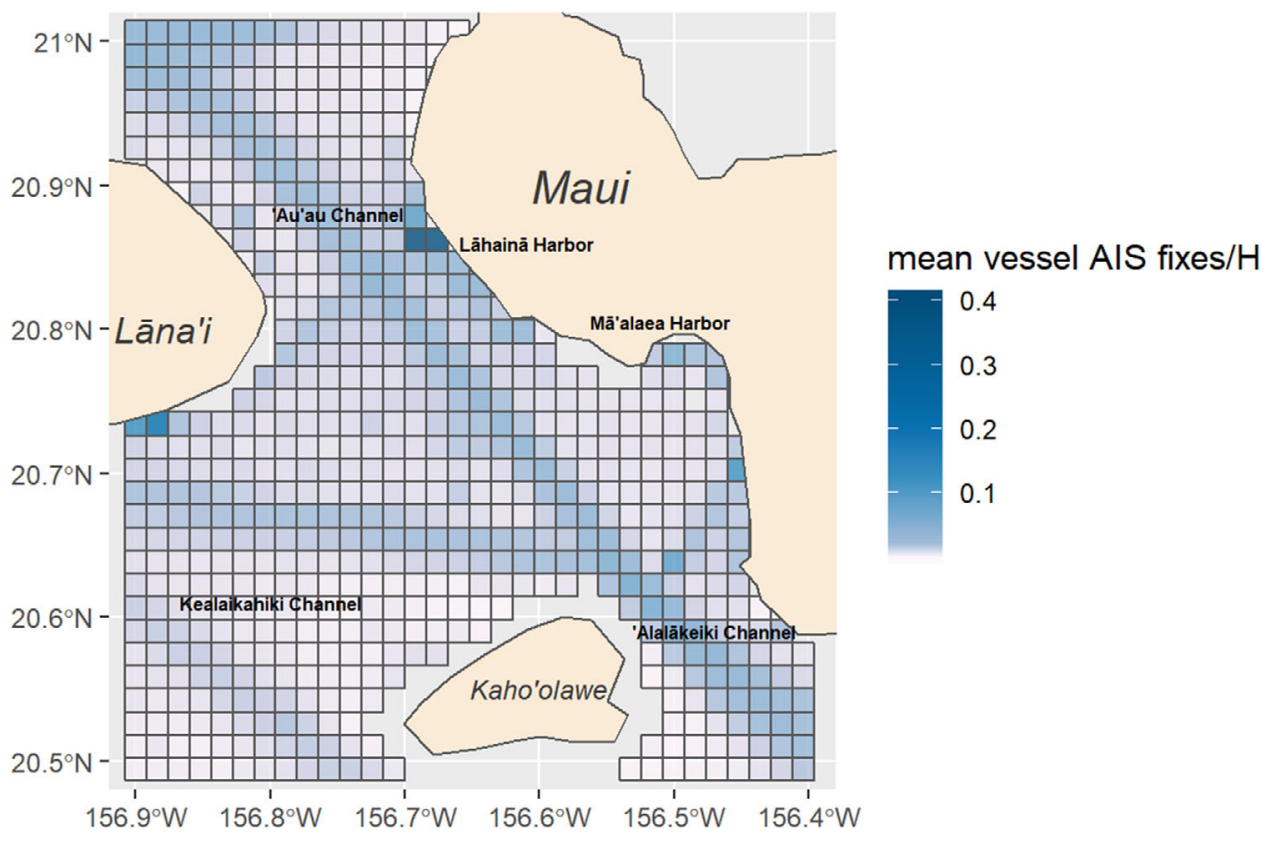

FIGURE 1 Location of the study area within the four-island region of Maui, Hawai'i, USA with mean vessel AIS fixes per hour per grid cell, data for all vessels equipped with AIS (see Methods section) using the study area from 2013 to 2017 (BOEM \& NOAA, 2019)

traffic facilitating a variety of marine tourism and recreational activities, along with local fisheries and shipping (Figure 1) (Department of Business Economic Development \& Tourism, 2015).

\subsection{Cetacean observations}

Sightings data were collected aboard tour boats using the community science application Whale and Dolphin Tracker (WDT), developed by Pacific Whale Foundation (PWF) (Currie et al., 2018). While WDT is open to the public, in this instance we restricted analyses to sightings recorded by naturalists who have completed a $60 \mathrm{~h}$ training programme focused on species and behaviour identification. The fleet of seven vessels and each naturalist had a user account for WDT, and only this subset was used to ensure species identification accuracy. Only presenceonly sighting locations were available, and sample bias in the form of numbers of sightings per grid cell was included in subsequent MaxEnt analyses to compensate for the uneven effort associated with PoP (Pearce \& Boyce, 2006).

Dolphin sighting data were collected from multiple whale-watching and snorkel trips departing from both Ma'alaea and Lahaina Harbors daily between 1 January 2013 and 31 March 2017. Vessel speeds ranged from 5-20 knots, and followed a non-systematic track, usually determined by weather and trip itinerary (e.g. snorkel site). Only sightings where the dolphin schools were approached and subsequently watched were used in analysis to ensure accuracy of species identification and calf presence. Encounter location (latitude and longitude) was recorded using WDT when the vessel was $\leq 150 \mathrm{~m}$ from the focal school.

\section{3 | Data processing}

The initial dataset consisted of 2852 sightings. Which were quality controlled to ensure accurate location of sightings. Where coordinates were identified as erroneous (such as outside of Maui or on land), we used the vessel's built-in GPS data to correct the coordinates by identifying the correct location of the vessel along the GPS track at the time of the sighting. For records where corrections of erroneous coordinates were not possible, the sightings were excluded from analyses.

\subsection{Environmental data}

Environmental data were gridded $(50 \times 50 \mathrm{~m})$ using the $\mathrm{R}$ package resample (Hesterberg, 2015) and associated with sightings.

We introduced four spatial variables in maximum entropy (maxent) models: bathymetry (50 m resolution) (Hawai'i Mapping Research Group, 2017), the presence/absence of coral reefs (Andréfouët et al., 2005), the proximity to the coast (meters) for each sighting (Natural Earth, 2017) and benthic roughness. Benthic roughness was estimated as the ratio of surface area to planimetric area to act as a proxy for benthic habitat type (Jenness, 2004). We also used a variable that could be associated with levels of anthropogenic activities: the proximity to urbanized coastal areas (meters) using information on urban cluster locations from census data as a proxy for coastal anthropogenic activity (State of Hawai'i Office of Planning, 2017). We also included oceanographic variables: tidal height (feet) originated from the NOAA station 1615680 at Kahului Harbour (NOAA, 2017b), sea surface temperature (SST) in degrees Celsius recorded every 30 min was sourced from 

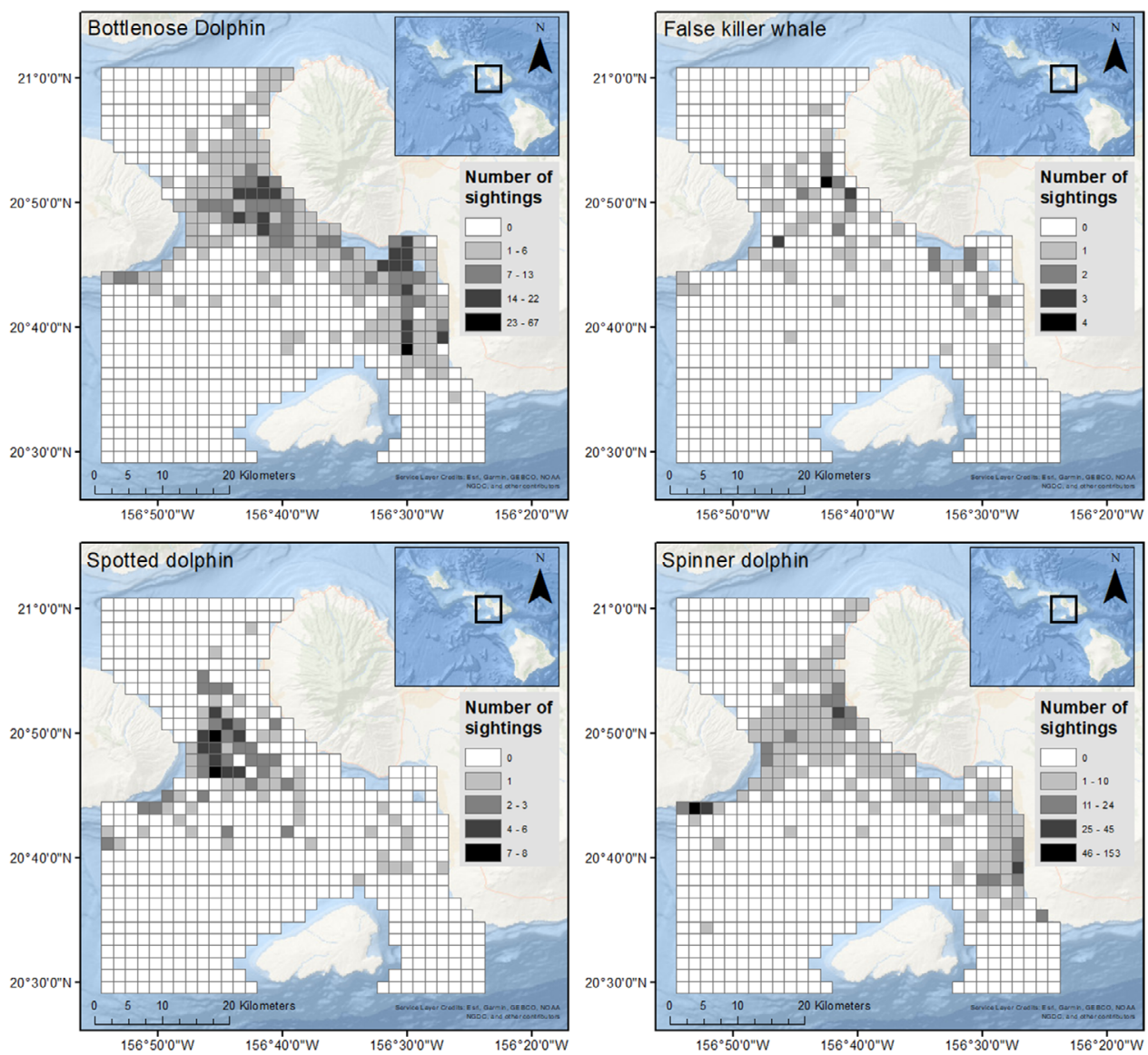

FIGURE 2 Number of sightings by species per grid cell in the study region

the NOAA data buoy at station 51203 in Kaumalapau, Lana'i (NOAA, 2017b) and satellite-derived ocean surface current dynamics, including zonal currents velocity $(\mathrm{m} / \mathrm{s})$, zonal maximum mask $(\mathrm{m} / \mathrm{s})$, meridional current velocity $(\mathrm{m} / \mathrm{s})$ and meridional current maximum mask $(\mathrm{m} / \mathrm{s})$ at a spatial resolution of $0.33 \mathrm{deg}$ (latitude) $\times 0.33 \mathrm{deg}$ (longitude) at a 5 -day temporal resolution were obtained from the Jet Propulsion Laboratory 'Physical Oceanography Distributed Active Archive Data Centre' (JPL PO.DAAC, 2017).

Finally, we included temporal variables: year, to account for interannual variability and any influence by the EI Niño-Southern Oscillation cycle, and season. As the oceanographic seasons in Hawai'i are not highly variable, we used the variance in SST (Figure 2) to define a 'Winter' season from October-April and a 'Summer' season from MaySeptember.

\subsection{Distribution model development}

We categorized sightings by species and whether calves were present or absent in the school. We modelled each sighting response variable separately using 'maxent' in the $\mathrm{R}$ package dismo using a regularization factor of 1 (Hijmans et al., 2017). We preferred to carefully select explanatory variables and rely on model validation rather than engage in a selection of penalization magnitude (Royle et al., 2012). The mod- els were trained on a $k$-folded subset of $70 \%$ of the data, created using the package cvTools (Alfons, 2015). To compensate for potential effort bias, an effort proxy distribution grid was established from the kernel density of sightings for all species; estimating the kernel utilization distribution assuming a bivariate normal kernel function using the R package adehabitatHR (Calenge, 2006). We selected 10,000 spatial background points using this bias pattern, and further subsampled 1050 background points from those across temporal environmental variables. We used those in the maxent models to assess the range of environmental conditions available so that the spatial distribution of the background points was equivalent to that of the presence records (Phillips, 2009; Syfert et al., 2013).

The maxent models were tested by adding and removing variables until an AUC > 0.5 was achieved indicating model performance was better than random, and the model with the highest AUC selected as the best fitting model for that species (Duque-Lazo et al, 2016 ; Franklin \& Miller, 2010). AUC does not cover all aspects of model relevance (Lobo et al, 2008), we therefore complemented this model selection step with estimates of model goodness-of-fit and accuracy. We evaluated the models by assessing their ability to predict the sightings in the remaining test subset of $30 \%$ of the sighting records. We used four evaluation statistics to evaluate model fit and predictive performance: (i) the area under the receiver-operating characteristic curve calculated with a Mann-Whitney $U$ statistic (AUC), to indicate 
discrimination performance with how much variation was captured by the model; (ii) the percentage correctly classified (PCC), which described predictive performance in how many of the test sightings were correctly predicted by the model, generated using the package PresenceAbsence (Freeman \& Moisen, 2015). We also used: (iii) the point biserial correlation coefficient between observed and predicted values (COR), which described the degree to which predictions were linearly related to the established probability of presence, taking into account how far predictions vary from the test values; and finally (iv) the intercept of regression of observed versus predicted values (Bias), which indicated if the predicted values from a model are over- or underestimates compared to true values, generated using the custom function 'ecalp' (Oppel et al., 2012; Phillips \& Elith, 2010). Each evaluation statistic provided information on a different aspect of model fit and performance and was examined separately for any evidence of poor performance and cohesively to come to an overall view of the model.

\subsection{Distribution patterns}

Final models for each sighting category were used to predict relative occurrence rate (ROR, the relative probability that a cell is contained in a collection of presence samples) from spatial and temporal variables for each species and school category (with or without calves). As it is the case for most presence-only distribution modelling efforts, we do not have a way to robustly test the assumptions needed to understand the relationship between ROR and probability of individual presence in a grid cell. However, the search strategy in which the vessels engage and the search intensity lead to a less effort biased sampling of the study area (Figure 2) than might be encountered in other community science project. We also accounted for a proxy of effort (Figure S1 in the Supporting Information) in the selection of background points. Therefore, we assumed that ROR was an appropriate estimate of relative probability of presence (Merow et al., 2013). As we work at a regional scale, our main focus was to understand the relative variability in occurrence rather than delineate species home range. Hence, the need to define absolute probability of occurrence was not warranted (Merow et al., 2013; Royle et al., 2012). Finally, this means that we are not able to compare the absolute 'distribution' (probability of presence) between the four studied species but this does not prevent comparing general patterns of distribution (e.g. offshore vs. inshore, etc). ROR was estimated for each grid cell of the study area based on the median values of contributing variables for that grid cell and iteratively estimated for each year and each season. ROR values for each seasonal conditions were generated by supplying the $25 \%$ quantile of SST for the winter season and the $75 \%$ quantile of SST for the summer season to account for SST contributions over and above seasonal effects in the models. Hence, cold predictions represent ROR for cold conditions (25\% quantile SST) during winter and warm predictions represent ROR for warm conditions (75\% quantile SST) during summer. Maps of the predicted ROR were generated using ggplot2 (Wickham et al., 2018).

\subsection{Assessing the influence of season on relative abundance}

To assess seasonal variation, we modelled the number of sightings as a function of season (summer vs. winter) using a Generalised Linear Model with a Poisson error structure. Observations in this model were the number of sightings of a given species per calendar month, with a total of five replicates from each study year. While we did not have an exact measure of effort heterogeneity between seasons, the number of trips during which sightings of any of the species were recorded in Winter (1521 trips) was roughly twice the number of trips recorded in Summer (896 trips). To ensure model assumptions had been met, graphical plots of the residual distribution were inspected for the presence of patterns or bias, which was not present.

\section{8 | Spatial association models}

We developed spatial mixed effects models to determine the association of ROR of schools with calves with the ROR of schools without calves and vessel traffic estimates. It is important to note that ROR represents central tendencies in species occurrence in each grid cells, and therefore the association models here only capture the overlap between typical vessel traffic in a grid cell and the likely presence of the species, discounting potential avoidance tactics the species might have (e.g. Lusseau, 2005). However, these avoidance tactics can themselves have conservation implications and therefore these association models help to highlight whether vessel traffic, as a constraint on habitat use, may be of concern for particular species. They also discount uncertainties associated with the fitting of the models to the data, the model validation seems to point to a lower risk associated with these errors changing the outcome of analyses on relative trends; which is why we do not make any inference beyond a description of potential spatial concordance. Vessel density was estimated each year (20132017) using the average number of automatic identification systems (AIS) fixes recorded per hour in each grid cell that year using data from the U.S. Marine Cadastre (BOEM \& NOAA, 2019). AIS is required for all vessel larger than $300 T$ and all passenger vessels regardless of size. While this represents only a subset of all vessel activities, it captures a broad representation of vessel traffic in the area. ROR was arcsinesquare root transformed, following investigation of the goodness-offit of the residual distribution with the assumed distributions, and all models assumed a Gamma distributed error structure with a log link function. All models included a random effect of 'year' and 'season' (as defined in the previous section using both season and SST) as well as a Matérn spatial correlation structure (Rousset \& Ferdy, 2014). The Matérn variogram function is composed of a gamma and a Bessel function and describes a generalized Gaussian spatial process with varying smoothness offering flexibility in its local behaviour.

We challenged the data with five spatial models for each species to determine the extent with which the ROR of schools with calves $\left(R^{\prime} R_{\text {calf }}\right)$ was associated with the ROR of schools without calves 
$\left(R_{\text {adult }}\right)$ and vessel density. In all models, $R_{\text {calf }}$ was the response variable. A 'null model' only fitted an intercept as fixed effect, 'adult

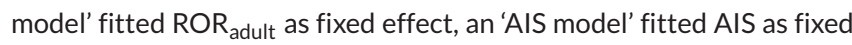
effect, an 'adult \& AIS model' fitted a fixed effect of AIS and ROR and finally an 'adult $\&$ AIS structured dispersion model' fitted a fixed effect of ROR adult $_{\text {and }}$ an effect of AIS on the variance dispersion of that relationship. The latter model helped to identify whether areas where $\mathrm{ROR}_{\text {calf }}$ departs more from ROR $\mathrm{R}_{\text {adult }}$ are also areas with greater vessel density.

We also assessed whether ROR adult was associated with vessel density by fitting two spatial mixed effects models similar to the ones developed for the $\mathrm{ROR}_{\text {calf }}$ response variable (null model and AIS model). Models were selected using marginal AIC. All spatial mixed effects models were developed and fitted using spaMm in R (Rousset \& Ferdy, 2014). We used this approach, rather than introduce vessel traffic as an explanatory variable in the MaxEnt models as we wanted to assess whether the predicted ROR might be associated with vulnerability to traffic risk. Finally, if an association between vessel traffic and distribution was detected we used a qualitative approach to determine a spatial index to identify vulnerability hotspots. This avoided further manipulation of the data via regularization or scaling to get all variables on a similar scale in a tractable manner. For cases, where AIS was retained as an explanatory variable, we determined the ROR top quintile cells and the AIS top quintile cells (both on a log scale given the distributions and assumptions of models fitted). We identified cells that were in both top quintiles. In cases where the structured dispersion model was retained, we estimated the residuals of the relationship between $R O R_{\text {calf }}$ and $R O R_{\text {adult }}$ and identified the top quintile of these residuals as a measure of relative risk. To further understand vulnerability in those cases, we also identified those cells were the residuals are in the top quintile, AIS is in the top quintile and $\mathrm{ROR}_{\text {calf }}$ is in the top quintile as a measure of risk. This identified locations where not only schools with calves are more likely to be present that schools without calves for that species, but they are also more often present overall. We engaged in the same process to estimate 'coldspots' with bottom quintiles.

\section{3 | RESULTS}

\section{1 | Sightings}

After quality control, the dataset contained 2757 sightings. The most frequently sighted species was spinner dolphins, totalling 1286 events. The highest sighting densities for spinner dolphins were recorded in shallow coastal waters and the Au'au channel (Figure 2). Bottlenose dolphins were sighted 1106 times, distributed the most widely of the four study species (Figure 2). Higher sighting densities of bottlenose dolphins occurred in the Au'au channel and Ma'alaea harbour. Spotted dolphins were sighted most commonly in the deeper areas of the Au'au channel and around Lana'i, with 272 sighting recorded in total (Figure 2). Finally, 93 sightings of false killer whales were distributed broadly across the study region (Figure 2 ).

\subsection{Distribution model performance and validation}

The models for all species were able to adequately discriminate species distribution patterns (AUC > 0.7) (Table 1) (Hosmer \& Lemeshow, 1989; Phillips \& Elith, 2010). The ability of the models to correctly predict the test sightings varied. PCC values varied, with the lowest being for the model of false killer whale schools with calves (58\%) and the highest for spinner dolphin schools without calves (99\%) (Table 1). COR estimates of how far predictions varied from the test values fit into two broad groups: spinner dolphin schools both with and without calves, along with bottlenose dolphin schools with calves had COR values above 0.3 , whereas all other values were $<0.1$ (Table 1). Bias showed the highest $(>6$ ) underestimation of occurrence for false killer whales and bottlenose dolphins, while other models had much lower values $(<0.6)$ (Table 1 ).

\subsection{Variables describing distribution}

The variable contribution was varied across models (Figure 3; Table S1 in the Supporting Information). Year was the most consistent contributing variable, ranked as third or higher for all models. There were differences in the variable contribution within all species between schools with and without calves, with spatial variables contributing more to the distribution of schools with calves than schools without calves.

\subsection{Predicted distribution patterns}

The predicted distributions revealed a variety of distribution patterns for each species. False killer whales and bottlenose dolphins showed similar distributions, with high ROR for schools without calves associated with coastline and urbanized area proximity to each species,

TAB LE 1 Statistics evaluating the predictive ability each maxent distribution model against test data

\begin{tabular}{llcccc} 
Species & Calf status & AUC & COR & Bias & PCC \\
False killer whale & Present & 0.92 & -0.06 & 0.001 & 0.58 \\
& Absent & 0.85 & -0.009 & 6.157 & 0.97 \\
\multirow{2}{*}{ Bottlenose dolphin } & Present & 0.76 & 0.54 & 0.008 & 0.98 \\
& Absent & 0.94 & -0.03 & 6.157 & 0.95 \\
\hline \multirow{2}{*}{ Spotted dolphin } & Present & 0.87 & 0.09 & -0.01 & 0.80 \\
& Absent & 0.97 & -0.01 & 0.003 & 0.96 \\
\multirow{2}{*}{ Spinner dolphin } & Present & 0.77 & 0.33 & -0.02 & 0.63 \\
& Absent & 0.93 & 0.32 & -0.03 & 0.99
\end{tabular}

Abbreviations: AUC, area under the receiver-operating characteristic curve; Bias, intercept of regression of observed vs. predicted values; COR, point biserial correlation coefficient between observed and predicted values; PCC, percentage correctly classified. 
Schools without calves
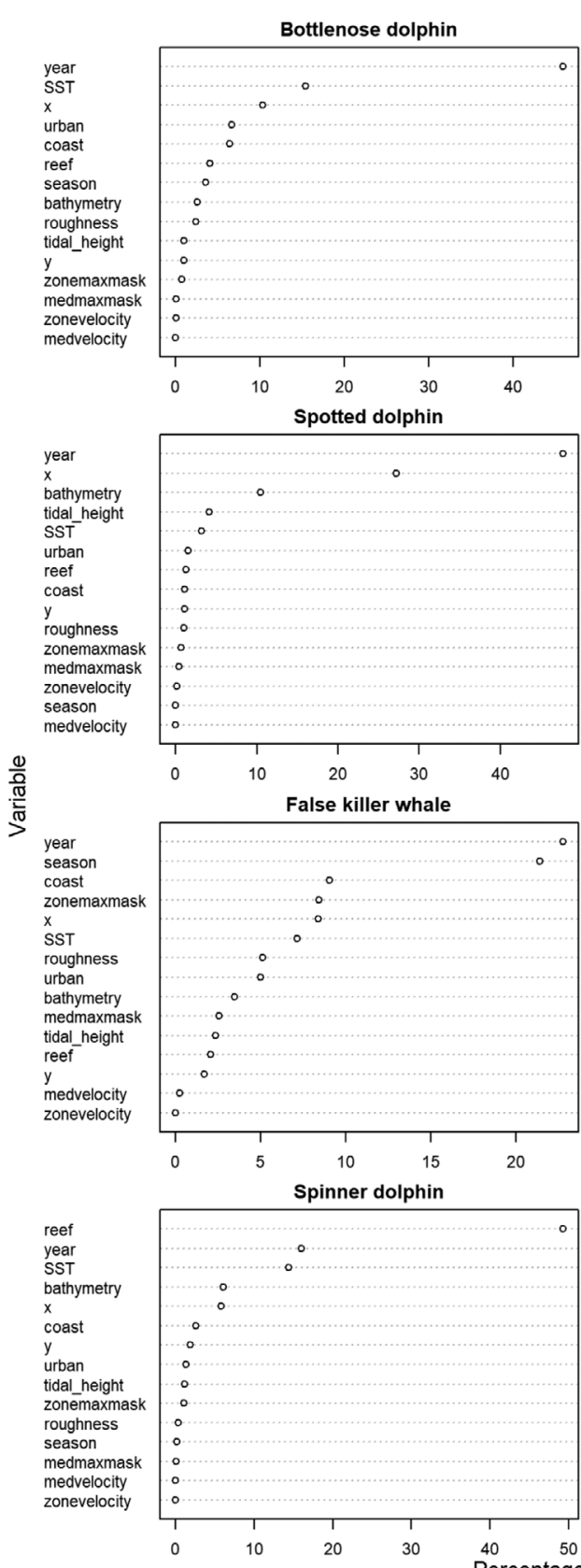

urban

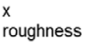
hness year bathymetry bathymetry
coast tidal_height season zonemaxmask reef zonevelocity zonevelocity
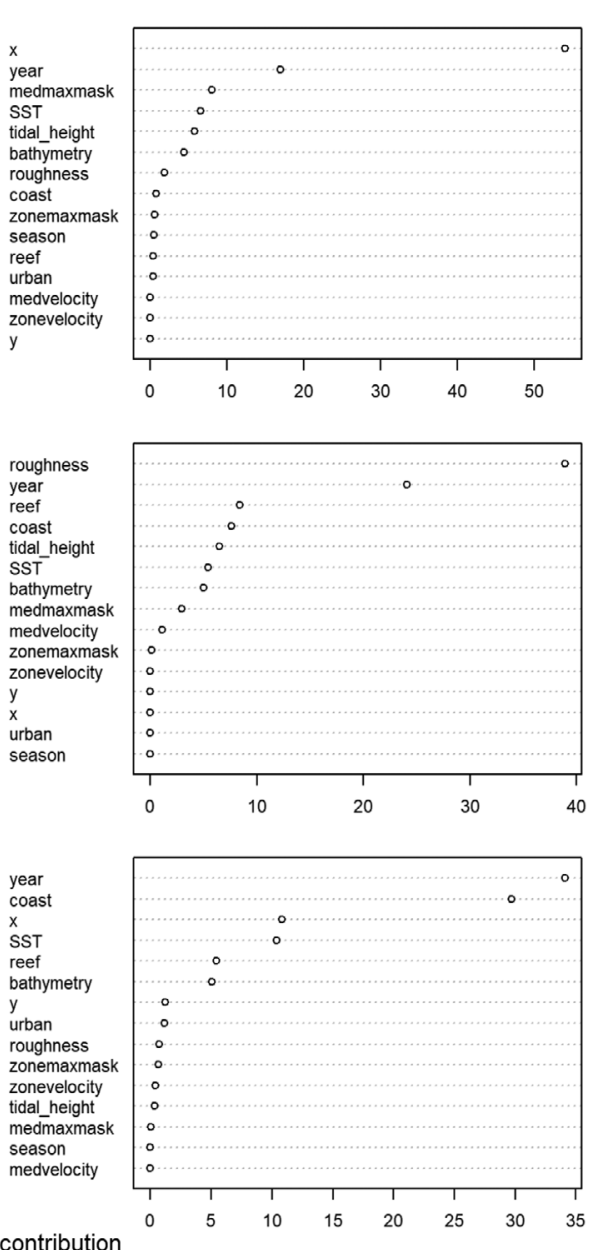

Schools with calves
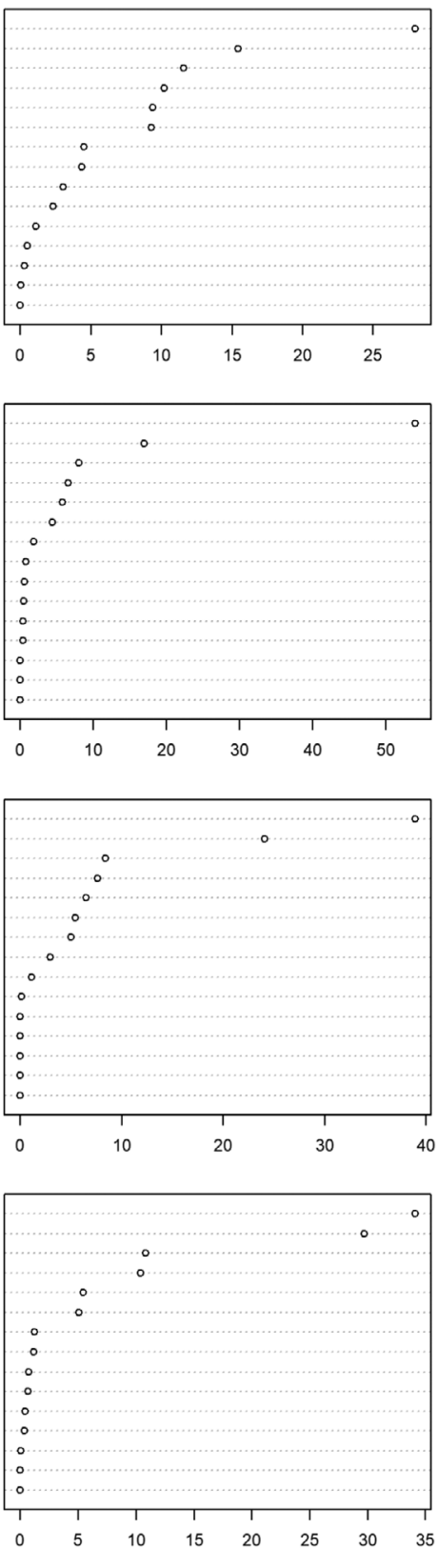

FIGURE 3 Variable contributions for each maxent distribution model. $x$ : longitude, $y$ : latitude, coast: coastal proximity, urban: urban cluster proximity, SST: sea surface temperature, season: winter and summer season, zonevelocity: zonal currents velocity, zonemaxmask: zonal maximum mask, medvelocity: meridonal current velocity, medmaxmask: meridional current maximum mask. (See Methods for detailed description of each variable)

respectively. All models exhibited differences within a species depending on whether the schools had calves, except for spotted dolphins (Figures 4; Figures S1-S9 in the Supporting Information).

\section{5 | Spatial associations of the distribution of schools with calves}

For all species, best models retained a fixed effect of $\mathrm{ROR}_{\text {adult }}$ associated with $\mathrm{ROR}_{\text {calf. }}$. However, this effect is negative: schools with calves did not follow the same distribution as schools without calves in the study area (Figure 4 and Tables 2 and 3; Figures S1-S9). The best models also included an effect of AIS on the dispersion of ROR $\mathrm{R}_{\text {calf }}$ for spinner dolphins and false killer whales. Therefore, the departure of $\mathrm{ROR}_{\text {calf }}$ from predictions based on the 'adult model' is associated with vessel density. We plotted the median residuals of the 'adult model' (median across year and season for each grid cell) for each species (Figure 5), and this departure is mainly associated with schools with calves being present more than expected in areas with high vessel density (Figure 6). 
TAB LE 2 Model selection of spatial association mixed effects model for each species and for each school category (calf: School with calves, no-calf: Schools without calves). Values are marginal AIC (best model in bold), NA when models were not fitted (see text for details). Model selected are in bold

\begin{tabular}{|c|c|c|c|c|c|c|}
\hline Species & $\begin{array}{l}\text { School } \\
\text { category }\end{array}$ & $\begin{array}{l}\text { Null model } \\
\text { (intercept only) }\end{array}$ & AIS model & Adult model & $\begin{array}{l}\text { Adult and AIS } \\
\text { model }\end{array}$ & $\begin{array}{l}\text { Adult and AIS } \\
\text { structured } \\
\text { dispersion }\end{array}$ \\
\hline Bottlenose dolphin & $\mathrm{ROR}_{\text {adult }}$ & $-28,795.0$ & $-28,796.0$ & NA & NA & NA \\
\hline False killer whale & $\mathrm{ROR}_{\text {calf }}$ & $-37,887.1$ & $-37,885.8$ & $-37,903.7$ & $-37,902.3$ & $-37,935.6$ \\
\hline Spotted dolphin & $\mathrm{ROR}_{\text {adult }}$ & $-24,738.7$ & $-24,742.2$ & NA & NA & NA \\
\hline \multirow[t]{2}{*}{ Spinner dolphin } & $\mathrm{ROR}_{\text {calf }}$ & $-43,001.9$ & $-43,009.6$ & $-44,334.5$ & $-44,344.9$ & $-44,429.7$ \\
\hline & $\mathrm{ROR}_{\text {adult }}$ & $-42,663.3$ & $-42,661.4$ & NA & NA & NA \\
\hline
\end{tabular}

Schools without calves

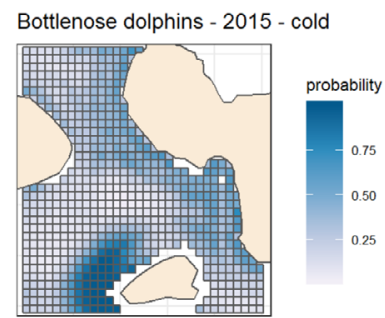

Spotted dolphins - 2015 - cold

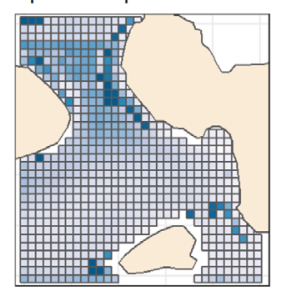

False killer whales - 2015 - cold

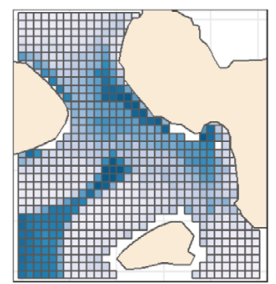

Spinner dolphins - 2015 - cold

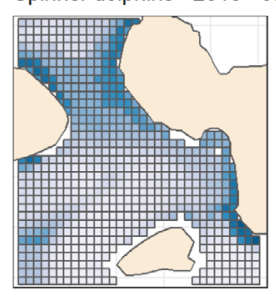

Schools with calves
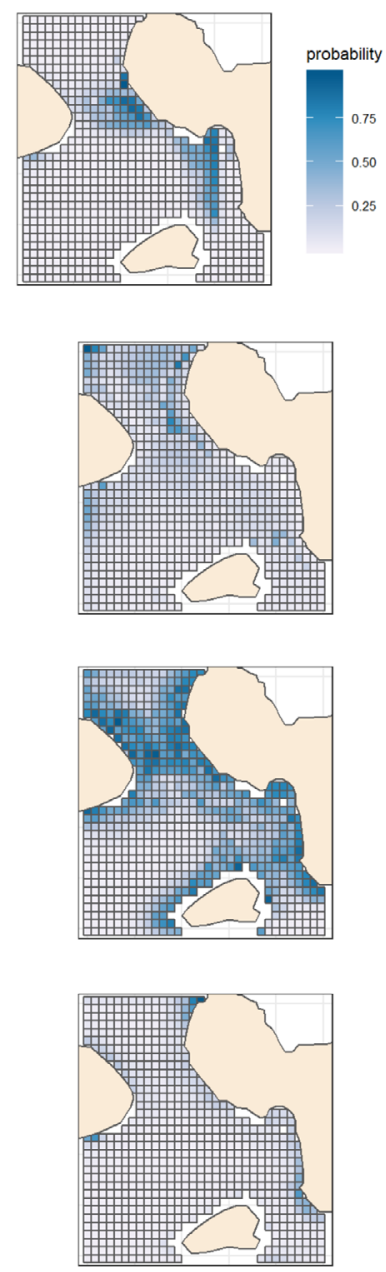

FIGURE 4 Predicted relative occurrence rate for schools with calves $\left(R O R_{\text {calf }}\right)$ and schools without calves $\left(R^{\prime} O R_{\text {adult }}\right)$ for each species for the year 2015 and winter season (SST set at $25 \%$ quantile of winter season SST). (See Figures S1-S9 for predictions for other years and seasons)

\subsection{Seasonal variation in sighting numbers}

Sighting numbers varied significantly with season: false killer whales and bottlenose dolphins were sighted more frequently in winter, while both spotted and spinner dolphins were sighted more frequently in summer (Figure 7).

\section{4 | DISCUSSION}

Maximum entropy modelling of presence-only observations provided meaningful and useful distribution models despite effort bias, complex sets of explanatory variables and limited sample sizes (Tyne et al., 2015). The ability to produce informative models with limited and unstructured data makes approaches like MaxEnt ideal for use with POP data, which has inherently heterogeneous effort distribution across environmental space, dictated by the vessels primary function. While POPs, like other community science sources, can introduce bias, they yield useful observations from which we can infer distribution information to guide the development of research surveys, conservation management plans and management decisions (Tyne et al., 2015). This study confirms that PoP can provide insight about species distribution at a regional scale from the substantial observations they provide where dedicated survey results are limited but a large tourism fleet exists, such as is the case in the four-island region of Maui. This information can guide the design of efficient monitoring schemes to determine density, abundance and their trends and inform in the interim adaptive geographic management plans.

\subsection{Variables associated with odontocete distribution}

The maxent models performed well in predicting the distribution of six of the eight school types modelled, while also demonstrating the complex interaction of variables that describe odontocete distribution. 
TAB LE 3 Summary of models retained for interpretation for each species. Spatial mixed effects model with a Gamma error structure (log link function), a Matérn spatial correlation structure and including a dispersion structured model. Response variable arcsine-square root transformed

\begin{tabular}{|c|c|c|c|}
\hline \multicolumn{4}{|c|}{$\begin{array}{l}\text { False killer whale } \mathrm{ROR}_{\text {calf }} \text { - Adult and AIS structured dispersion } \\
\text { model (Matérn: } \nu=0.756, \rho=2.746 \text { ) }\end{array}$} \\
\hline \multicolumn{4}{|c|}{ Fixed effects } \\
\hline Term & $\begin{array}{l}\text { Coefficient } \\
\text { estimate }\end{array}$ & $\begin{array}{l}\text { Conditional } \\
\text { SE }\end{array}$ & $t$-value \\
\hline Intercept & -1.89 & 1.640 & -1.15 \\
\hline $\mathrm{ROR}_{\text {adult }}$ & -0.018 & 0.005 & -3.80 \\
\hline \multicolumn{4}{|c|}{ Random effects } \\
\hline Term & $\begin{array}{l}\text { Variance } \\
\text { estimate }\end{array}$ & $\begin{array}{l}\text { Intercept } \\
\text { estimate }\end{array}$ & $\begin{array}{l}\text { Conditional } \\
\text { SE }\end{array}$ \\
\hline Year & 0.0317 & -3.452 & 0.707 \\
\hline Season & 0.0266 & -3.628 & 1.411 \\
\hline Long + Lat & 5.379 & 1.682 & 0.056 \\
\hline \multicolumn{4}{|c|}{ Residual variation model } \\
\hline Term & $\begin{array}{l}\text { Coefficient } \\
\text { estimate }\end{array}$ & $\begin{array}{l}\text { Conditional } \\
\text { SE }\end{array}$ & \\
\hline Intercept & -7.62 & 0.020 & \\
\hline AIS & 2.93 & 0.584 & \\
\hline \multicolumn{4}{|c|}{$\begin{array}{l}\text { Spinner dolphin } \mathrm{ROR}_{\text {calf }} \text { - Adult and AIS structured dispersion model } \\
\text { (Matérn: } \nu=0.908, \rho=7.464 \text { ) }\end{array}$} \\
\hline \multicolumn{4}{|c|}{ Fixed effects } \\
\hline Term & $\begin{array}{l}\text { Coefficient } \\
\text { estimate }\end{array}$ & $\begin{array}{l}\text { Conditional } \\
\text { SE }\end{array}$ & $t$-value \\
\hline Intercept & -0.535 & 0.915 & -0.58 \\
\hline $\mathrm{ROR}_{\text {adult }}$ & -0.443 & 0.011 & -39.36 \\
\hline \multicolumn{4}{|c|}{ Random effects } \\
\hline Term & $\begin{array}{l}\text { Variance } \\
\text { estimate }\end{array}$ & $\begin{array}{l}\text { Intercept } \\
\text { estimate }\end{array}$ & $\begin{array}{l}\text { Conditional } \\
\text { SE }\end{array}$ \\
\hline Year & 0.1833 & -1.70 & 0.703 \\
\hline Season & 0.39 & -0.94 & 1.274 \\
\hline Long + Lat & 2.496 & 0.91 & 0.056 \\
\hline \multicolumn{4}{|c|}{ Residual variation model } \\
\hline Term & $\begin{array}{l}\text { Coefficient } \\
\text { estimate }\end{array}$ & $\begin{array}{l}\text { Conditional } \\
\text { SE }\end{array}$ & \\
\hline Intercept & -6.57 & 0.020 & \\
\hline AIS & 4.54 & 0.580 & \\
\hline \multicolumn{4}{|c|}{ Spotted dolphin $\mathrm{ROR}_{\text {calf }}$ - Adult model (Matérn: $\left.\nu=0.398, \rho=1.542\right)$} \\
\hline \multicolumn{4}{|c|}{ Fixed effects } \\
\hline Term & $\begin{array}{l}\text { Coefficient } \\
\text { estimate }\end{array}$ & $\begin{array}{l}\text { Conditional } \\
\text { SE }\end{array}$ & $t$-value \\
\hline Intercept & -1.414 & 0.822 & -1.72 \\
\hline $\mathrm{ROR}_{\text {adult }}$ & -0.019 & 0.0023 & -8.10 \\
\hline
\end{tabular}

(Continues)
TABLE 3 (Continued)

\begin{tabular}{|c|c|c|c|}
\hline \multicolumn{4}{|c|}{ Random effects } \\
\hline Term & \multicolumn{3}{|l|}{$\begin{array}{l}\text { Variance } \\
\text { estimate }\end{array}$} \\
\hline Year & \multicolumn{3}{|l|}{0.131} \\
\hline Season & \multicolumn{3}{|l|}{0.001} \\
\hline Long + Lat & \multicolumn{3}{|l|}{1.26} \\
\hline \multicolumn{4}{|c|}{$\begin{array}{l}\text { Bottlenose dolphin } \operatorname{ROR}_{\text {calf }} \text { - Adult and AIS structured dispersion } \\
\text { model (Matérn: } \nu=0.94, \rho=5.21 \text { ) }\end{array}$} \\
\hline \multicolumn{4}{|c|}{ Fixed effects } \\
\hline Term & $\begin{array}{l}\text { Coefficient } \\
\text { estimate }\end{array}$ & $\begin{array}{l}\text { Conditional } \\
\text { SE }\end{array}$ & $t$-value \\
\hline Intercept & -5.708 & 2.402 & -2.376 \\
\hline $\mathrm{ROR}_{\text {adult }}$ & -0.221 & 0.008 & -27.714 \\
\hline \multicolumn{4}{|c|}{ Random effects } \\
\hline Term & \multicolumn{3}{|l|}{$\begin{array}{l}\text { Variance } \\
\text { estimate }\end{array}$} \\
\hline Year & \multicolumn{3}{|l|}{0.026} \\
\hline Season & \multicolumn{3}{|l|}{0.076} \\
\hline Long + Lat & \multicolumn{3}{|l|}{16.78} \\
\hline
\end{tabular}

The models also highlighted the variability in odontocete distribution in the four-island marine region, as interannual variability was estimated to be as either the most or second most significant variable for pods without calves for all species. The variable contributions suggest that likely habitat preferences for schools containing calves involves a greater complexity of factors than that for schools without calves. The retention of urban proximity in the models, a proxy for coastal activity, highlights the association of the species distribution with permanently altered habitat which can expose them to potential anthropogenic risks.

Given the predicted distributions, each species has different ecological requirements. False killer whales and bottlenose dolphins had high ROR in the Kealaikahiki channel. Pantropical spotted dolphins were distributed throughout the entire survey area. The patterns suggested by our models are consistent with established preference for deeper water in both spotted dolphins and false killer whales, with both models suggesting higher ROR in the deeper region in the 'Alalākeiki and 'Au'au channels (Courbis et al., 2014). The similarity between the distribution of reef patches and that of the preferred benthic habitat type for spinner dolphin resting areas was reflected in their predicted distribution. Spinner dolphins showed a clear pattern of using shallow, sheltered areas, which is consistent with what has been previously established for their diurnal resting and foraging behaviour (Carretta et al., 2020). Areas with these physical characteristics are popular with recreational vessels offering snorkel or diving experiences. This supports the need for management of areas wider than that proposed area in south Maui, in order to successfully provide protection for spinner dolphin from adverse impacts of disturbance (Stack et al., 2020). 

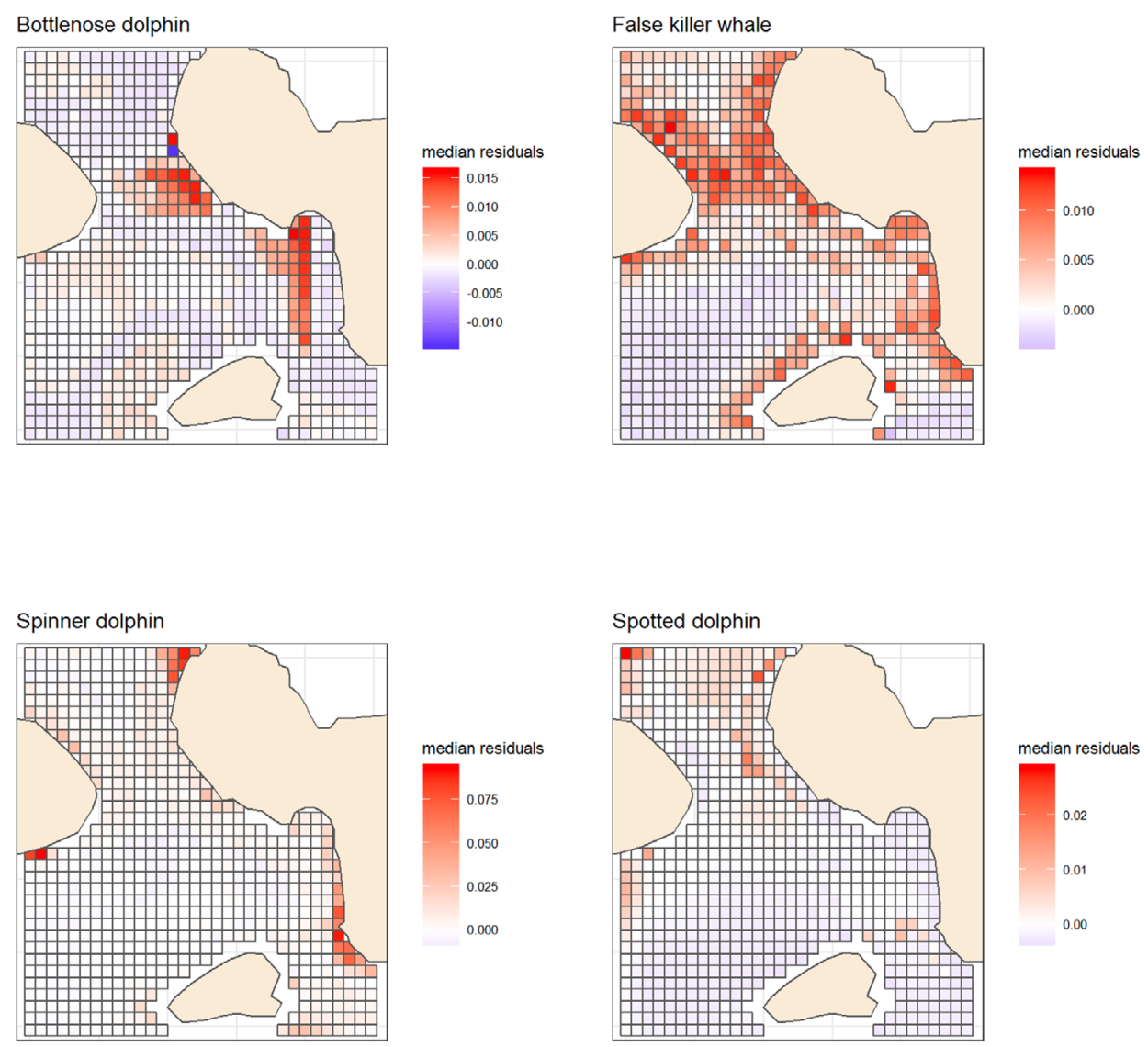

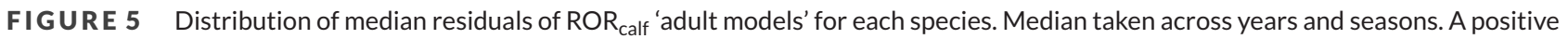
median residual value (red) corresponds to ROR $_{\text {calf }}$ being consistently larger than predicted by adult models across years and seasons

The presence of calves in a school seem to change the distribution of spinner dolphin and false killer whale schools. For all species, the area with a high ROR for schools with calves was smaller than those without (Figures 3 and 4).

The seasonal dynamics of relative abundance in the region showed varying trends. The false killer whales and bottlenose dolphins were more frequently sighted in winter, while the inverse was true for the spinner and spotted dolphins. However, the influence of varying POP routes and vessel behaviour within each season cannot be ruled out; during the humpback whale season, when whale watching occurs, POP movements are more varied across the study region, whereas out of season vessels movement is more rigid to travelling between designated locations.

\section{2 | Vessel traffic overlap with dolphin distribution}

There is a lot of vessel activity in the study area and therefore more scope for conservation challenges to emerge from both lethal collisions (Tyne et al., 2015) and non-lethal repeated dolphin activity disruption and stress response elicitation if it overlaps with locations the species use more regularly (Carretta et al., 2020). It is concerning that the distribution of school with calves is associated with high traffic areas for two species (Figure 5). These schools have increased energetic constraints and lessened abilities to avoid collisions, which means that they are more sensitive to the risks posed by vessel traffic (Tyne et al., 2015). This overlap in distribution is therefore a conservation concern. The proximity of high ROR areas to the coastline around the southwest of Maui island and western Lanai also means there is risk associated with other anthropogenic activities, such as marine recreation or sports originating from land (e.g. paddle boarding or snorkelling) (National Marine Fisheries Service, 2016). These types of activity are most likely to impact the spinner dolphins due to their use of coastal resting areas during the daytime. It is worth noting that the data for this model came from AIS, meaning it reflects shipping vessels, larger fishing vessels and all passenger vessels. There are numerous other smaller vessels transiting this region daily, and these data represent the minimum exposure to vessel traffic.

\subsection{Implications for management and conservation}

Anthropogenic activities can affect the conservation status of marine species not only through lethal incidents but also by influencing offspring survival and by affecting the energetic budget of a mother with her offspring (Manlik et al., 2016; Pirotta et al., 2018). Managing these 

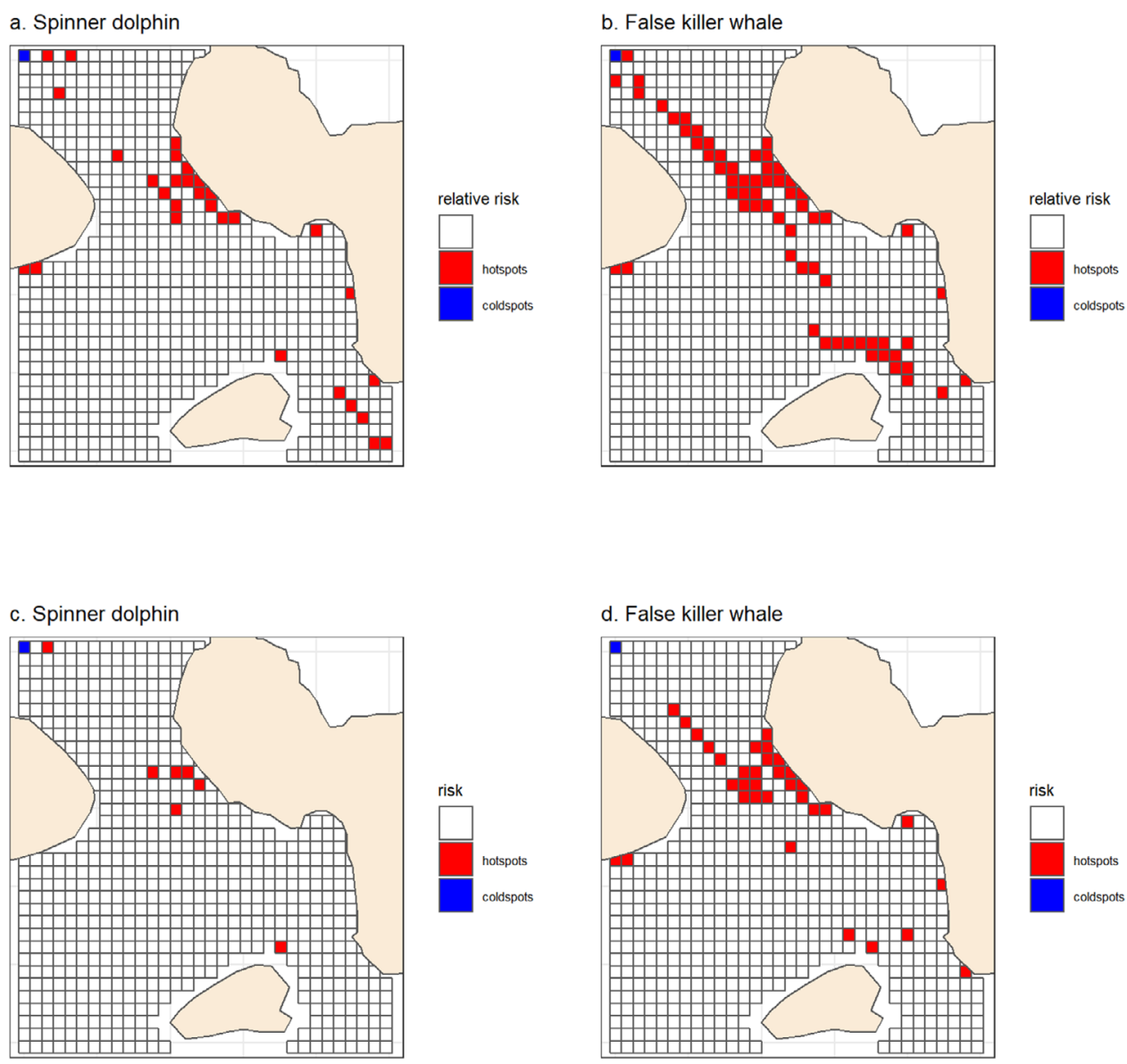

FIGURE 6 Cells identified as hot- and cold-spots of potential interactions between schools with calves and vessel traffic for spinner dolphins ( $a$ and $c$ ) and false killer whales ( $b$ and d). (a) and (b) present cells that are in the top (red) and bottom (blue) quintiles of both RORcalf residuals (see Methods) and vessel traffic. (c) and (d) present cells that are in the top (red) and bottom (blue) quintile of RORcalf, RORcalf residuals and vessel traffic
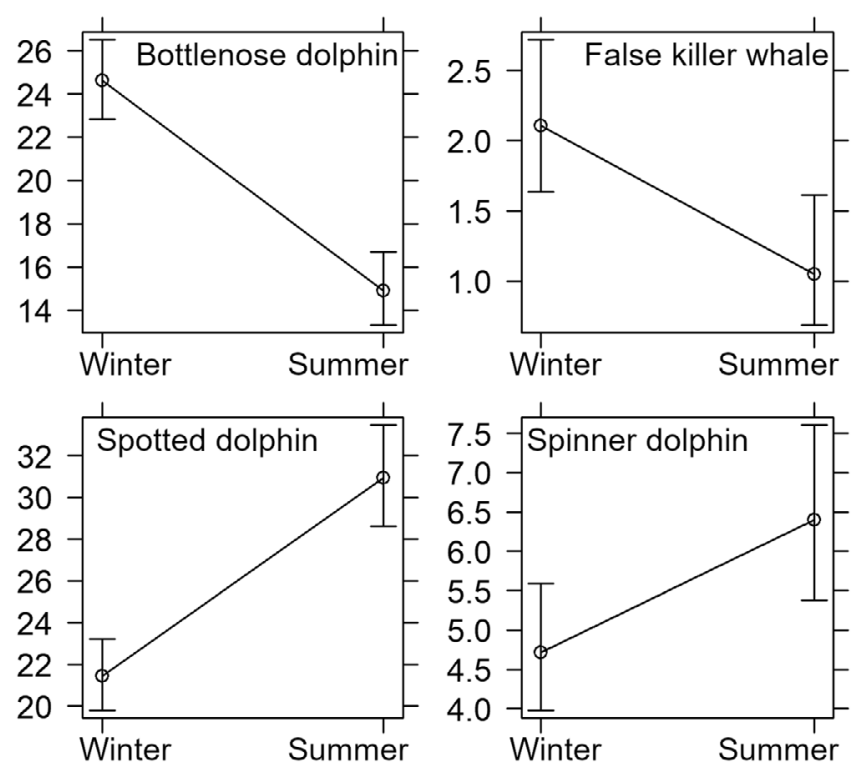

FIGURE 7 Predicted changes in the number of sightings of each study species depending on season. Error bars are $95 \%$ confidence intervals impacts can be particularly challenging in the context of marine populations, where both species distribution and anthropogenic activities vary both spatially and temporally (Van Cise et al., in press). Quantifying either of these can be difficult due to the dynamic nature of the marine environment, particularly when trying to establish the drivers of species distribution whilst incorporating individual movement patterns (Thorson et al., 2017). This lends additional complexity to attempts to assess the degree of spatio-temporal overlap of marine populations with anthropogenic activity, which is essential to inform effective management (Stack et al., 2020; Thorson, Jannot, \& Somers, 2017). The management of explicit spatial areas can be an effective tool for reducing the pressures on mobile species (CBD, 2008), such as the approach used by NOAA in establishing the Main Hawaiian Islands longline fishing prohibited area and Southern Exclusion Zone in order to manage the impact of mortality from interaction with the longline fishery (NOAA, 2012). Another example of spatial management is seen in northern right whales (Eubalena glacialis) that are at high risk for collision. NOAA has introduced a dynamic reporting system for vessels in northern right whale's critical habitat to mitigate the risk of collision including a speed restriction (Silber et al., 2015). 
Habitat modelling can be used to inform marine spatial planning, by ensuring preservation is focused on regions where ecosystem services are key to productivity and ecological coherence (Sundblad et al. 2011). Our findings highlight that dolphins use areas that are heavily used by vessel and recreational traffic. We have identified here particular location where it would be advantageous to assess the possibility to develop similar warning systems for commercial and recreational boaters. This is of particular importance where abundance estimates or habitat use is declining, such as is the case in the bottlenose dolphin population in the four-island region (Van Cise et al., in press). These results begin to address some of these questions, although the distribution of recreational activity, assumed correlated with coastal urbanization, remains a large, unquantified pressure in the study region.

This study site is part of the HIHWNMS meaning it has a management plan in place, along with no-take regulations associated with the Marine Mammal Protection Act and, for the insular population of false killer whales, the Endangered Species Act. While some HIHWNMS policies, such as those restricting the dumping of materials or destruction of habitat, provide protection for all marine life, other policies, such as approach limits, only currently apply to humpback whales (Carretta et al., 2020). There are voluntary programmes in place focusing on dolphins, such as the PWF's 'Be Dolphin Wise' code of conduct and NOAA's 'Dolphin Smart' programme, promoting practices attempting to limit the disturbance caused by dolphin watching vessels. However, participation in these programmes is voluntary and can also remain largely unknown for recreational vessel operators. NOAA has also proposed a rule to prohibit approaching spinner dolphins closer than 50 yards in the four-island region, but this is yet to become final (NOAA, 2016).

Given the endangered status of the insular population of false killer whales in Hawai'i (Tyne et al., 2015), this study highlights an areabased management option to help with its recovery. There are welldefined coastal areas where false killer whale schools with calves are more likely to be observed (Figure 5). The key conservation threat for this population is injuries and death associated with fisheries interactions (Baird et al., 2015), and understanding trends in abundance is a research priority of the take reduction plan (Baird et al., 2014). Fishery interaction, specifically with the nearshore yellowfin tuna fishery, poses a conservation concern for spotted dolphins in the main Hawaiian islands where fishing effort has been documented to target spotted dolphin schools (Baird \& Webster, 2020). We should explore whether decreasing anthropogenic pressures in areas where calves are observed more could increase the resilience of the population. The spatio-temporal variation in exposure to anthropogenic pressure also needs further exploration, alongside investigations into any variations in sensitivity to such pressures, as is present in spinner dolphins during resting periods (Stack et al., 2020). This study also highlights that resting bays are not the only locations where spinner dolphins are exposed to anthropogenic pressures (Tyne et al., 2015) and that the management of non-lethal anthropogenic stressors on this species should include a more comprehensive spatial management plan (Stack et al., 2020) which incorporates the spatio-temporal variations in the overlap of target species with anthropogenic activity (Thorson et al., 2017).

\section{ACKNOWLEDGEMENTS}

We would like to thank the members and supporters of Pacific Whale Foundation who provided financial support for development of the Whale \& Dolphin Tracker application. We additionally thank the PacWhale Eco-Adventures captains and naturalists that contributed to data collection and the Pacific Whale Foundation research interns who assisted with data management. Finally, we would like to thank the editor and two anonymous reviewers whose comments greatly improved the manuscript.

\section{AUTHORS' CONTRIBUTIONS}

HS, SHS, JJC and DL designed the study. JJC and SHS collected some of the data and coordinated the collection and curation of the whole dataset. DL and HS designed the analytical approach. HS and DL carried out analyses. HS wrote the manuscript with input from DL, SHS and JJC. All authors gave final approval for publication.

\section{DATA AVAILABILITY STATEMENT}

Data for this article can be found at https://github.com/dlusseau/ HawaiiMaxEnt and it is also available from Zenodo https://doi.org/10. 5281/zenodo.4674612 (Lusseau, 2021).

\section{PEER REVIEW}

The peer review history for this article is available at https://publons. com/publon/10.1002/2688-8319.12065.

\section{ORCID}

David Lusseau (D) https://orcid.org/0000-0003-1245-3747

\section{REFERENCES}

Alfons, A. (2015). Package 'cvTools'. https://cran.r-project.org/package= cvTools

Andréfouët, S., Muller-Karger, F. E., Robinson, J. A., Kranenburg, C. J., TorresPulliza, D., Spraggins, S. A., \& Murch., B. (2005). Global assessment of modern coral reef extent and diversity for regional science and management applications: a view from space. In Proceedings of 10th International Coral Reef Symposium, Okinawa, Japan, June 28- July 2, 2004 (pp. 1732-1745). International Society for Reef Studies and Japanese Coral Reef Society.

Baird, R. W., Webster, D. L., Aschettino, J. M., Schorr, G. S., \& McSweeney, D. J. (2013). Odontocete cetaceans around the main Hawaiian Islands: Habitat use and relative abundance from small-boat sighting surveys. Aquatic Mammals, 39(3), 253-269. https://doi.org/10.1578/AM.39.3. 2013.253

Baird, R. W., Bernard, H., Dalzell, P., Ishizaki, A., Gilman, E., La Grange, J., ..., \& Steen, R. (2014). False killer whale take reduction plan research priorities. https://www.fisheries.noaa.gov/webdam/download/70969546

Baird, R. W., Mahaffy, S. D., Gorgone, A. M., Cullins, T., McSweeney, D. J., Oleson, E. M., Bradford, A. L., Barlow, J., \& Webster, D. L. (2015). False killer whales and fisheries interactions in Hawaiian waters: Evidence for sex bias and variation among populations and social groups. Marine Mammal Science, 31(2), 579-590. https://doi.org/10.1111/mms.12177

Baird, R. W., \& Webster, D. L. (2020). Using dolphins to catch tuna: Assessment of associations between pantropical spotted dolphins and 
yellowfin tuna hook and line fisheries in Hawai' i. Fisheries Research., 230, 105652. https://doi.org/10.1016/j.fishres.2020.105652

Béchet, A., Giroux, J. F., \& Gauthier, G. (2004). The effects of disturbance on behaviour, habitat use and energy of spring staging snow geese. Journal of Applied Ecology, 41(4), 689-700. https://doi.org/10.1111/j.0021-8901. 2004.00928.x

Beissinger, S. R., \& Peery, M. Z. (2007). Reconstructing the historic demography of an endangered seabird. Ecology, 88(2), 296-305. https://doi.org/ 10.1890/06-0869.

Bureau of Ocean Energy Management (BOEM) and National Oceanic and Atmospheric Administration (NOAA) (2019). MarineCadastre.gov. Zone 4, 2013-2017.marinecadastre.gov/data.

Calenge, C. (2006). The package 'adehabitat' for the R software: A tool for the analysis of space and habitat use by animals. Ecological Modelling, 197(3-4), 516-519. https://doi.org/10.1016/j.ecolmodel.2006.03.017

Carretta, J. V., Forney, K. A., Oleson, E. M., Weller, D. W., Lang, A. R., Baker, J., ..., Brownell, R. L. Jr. (2020). U.S. Pacific marine mammal stock assessments: 2019. NOAA technical memorandum NOAA-TM-NMFS-SWFSC629

Carrillo, M., \& Ritter, F. (2010). Increasing numbers of ship strikes in the Canary Islands: Proposals for immediate action to reduce risk of vesselwhale collisions. Journal of Cetacean Research and Management, 11, 131138.

CBD. (2008). Decision IX/20, Annex 1 Scientific criteria for identifying ecologically or biologically significant marine areas in need of protection in open-ocean waters and deep-sea habitats. Bonn.

Courbis, S., Baird, R. W., Cipriano, F., \& Duffield, D. (2014). Multiple populations of pantropical spotted dolphins in Hawaiian waters. Journal of Heredity, 105(5), 627-641. https://doi.org/10.1093/jhered/esu046

Crooks, K. R. (2002). Relative sensitivities of mammalian carnivores to habitat fragmentation. Conservation Biology, 16(2), 488-502. https://doi.org/ 10.1046/j.1523-1739.2002.00386.x

Currie, J. J., Stack, S., \& Kaufman, G. (2018). Conservation and education through ecotourism: Using citizen science to monitor cetaceans in the four-island region of Maui, Hawai' i. Tourism in Marine Environments, 13(23), 65-71. https://doi.org/10.3727/154427318X15270394903273

Currie, J. J., Stack, S. H., McCordic, J. A., \& Roberts, J. (2018) Utilizing occupancy models and platforms-of-opportunity to assess area use of mother-calf humpback whales. Open Journal of Marine Science, 8, 276292. https://doi.org/10.4236/ojms.2018.82014

Department of Business Economic Development \& Tourism. (2015). State of Hawai'i Data Book.

Duque-Lazo, J., van Gils, H., Groen, T. A., \& Navarro-Cerrillo, R. M. (2016). Transferability of species distribution models: The case of Phytophthora cinnamomi in Southwest Spain and Southwest Australia. Ecological Modelling, 320, 62-70. https://doi.org/10.1016/j.ecolmodel.2015.09.019

Elith, J., Graham, C. H., Anderson, R. P., Dudik, M., Ferrier, S., Guisan, A., Hijmans, R. J., Huettmann, F., Leathwick, J. R., Lehmann, A., Li, J., Lohmann, L. G., Loiselle, B. A., Manion, G., Moritz, C., Nakamura, M., Nakazawa, Y., Overton, J. M.cC. M., Peterson, A. T., ..., Zimmermann, N. E. (2006). Novel methods improve prediction of species' distributions from occurrence data. Ecography, 29(2), 129-151.4https://doi.org/10.1111/j.2006. 0906-7590.04596.x

Franklin, J., \& Miller, J. A. (2010). mapping species distributions: Spatia inference and prediction. Cambridge University Press. https://doi.org/10. 1017/CBO9780511810602

Freeman, E. A., \& Moisen, G. (2015). PresenceAbsence: An R package for presence absence analysis . Journal of Statistical Software, 23, 1-31. https: //doi.org/10.18637/jss.v023.i11

Hawai'i Mapping Research Group. (2017). Main Hawaiian Islands Multibeam bathymetry and backscatter synthesis. http://www.soest.hawaii. edu/hmrg/multibeam/index.php

Hesterberg, T. (2015). Package ' resample'. https://CRAN.R-project.org/ package $=$ resample.
Hijmans, R. J., Phillips, S., Leathwick, J., \& Elith, J. (2017). dismo: Species distribution modeling. https://doi.org/10.1016/j.jhydrol.2011.07.022

Hosmer, D. W., \& Lemeshow, S. (1989). Applied logistic regression (1st ed.). John Wiley \& Sons.

IUCN Marine Mammal Protected Areas Task Force. (2018). Guidance on the use of selection criteria for the identification of Important Marine Mammal Areas (IMMAs). (March), 82. Author.

Jenness, J. S. (2004). Calculating landscape surface area from digital elevation models. Wildlife Society Bulletin, 32(3), 829-839. https://doi.org/10. 2193/0091-7648(2004)032\%5b0829:CLSAFD\%5d2.0.CO;2

JPL PO.DAAC. (2017). OSCAR third degree resolution ocean surface currents. Earth Space Research, JPL.

Kiszka, J., Macleod, K., van Canneyt, O., Walker, D., \& Ridoux, V. (2007). Distribution, encounter rates, and habitat characteristics of toothed cetaceans in the Bay of Biscay and adjacent waters from platformof-opportunity Data. ICES Journal of Marine Science, 64(5), 1033-1043. https://doi.org/10.1093/icesjms/fsm067

Lobo, J. M., Jiménez-valverde, A., \& Real, R. (2008). AUC: A misleading measure of the performance of predictive distribution models. Global Ecology and Biogeography, 17(2), 145-151. https://doi.org/10.1111/j.1466-8238. 2007.00358.x

Lusseau, D. (2005). Residency pattern of bottlenose dolphins Tursiops spp. in Milford Sound, New Zealand, is related to boat traffic. Marine Ecology Progress Series, 295, 265-272. https://doi.org/10.3354/meps295265s

Lusseau, D. (2021). Pacific Whale Foundation data used in Self et al. (2021). https://doi.org/10.5281/zenodo.4674612.

Manlik, O. (2019). The importance of reproduction for the conservation of slow-growing animal populations. In Advances in experimental medicine and biology (Vol., 1200, pp. 13-39). Springer. https://doi.org/10.1007/ 978-3-030-23633-5_2

Manlik, O., Mcdonald, J. A., Mann, J., Raudino, H. C., Bejder, L., Krützen, M., ..., \& Sherwin, W. B. (2016). The relative importance of reproduction and survival for the conservation of two dolphin populations. Ecology and Evolution, 6(11), 3496-3512. https://doi.org/10.1002/ece3.2130.

Merow, C., Smith, M. J., \& Silander, J. A. (2013). A practical guide to MaxEnt for modeling species' distributions: What it does, and why inputs and settings matter. Ecography, 36(10), 1058-1069. https://doi.org/10.1111/ j.1600-0587.2013.07872.x

Moura, A. E., Sillero, N., \& Rodrigues, A. (2012). Common dolphin (Delphinus delphis) habitat preferences using data from two platforms of opportunity. Acta Oecologica, 38, 24-32. https://doi.org/10.1016/j.actao.2011. 08.006

National Marine Fisheries Service. (2016). Approach regulations for humpback whales in waters surrounding the Islands of Hawai'i under the Marine Mammal Protection Act. https://www.regulations.gov/docket/ NOAA-NMFS-2016-0046

Natural Earth. (2017). World map data from Natural Earth. https://CRAN.Rproject.org/package=rnaturalearth

NOAA. (2012). Taking of marine mammals incidental to commercial fishing operations: False Killer Whale Take Reduction Plan. https://www.federalregister.gov/documents/2012/11/29/201228750/taking-of-marine-mammals-incidental-to-commercial-fishingoperations-false-killer-whale-take

NOAA. (2013). False killer whale (Pseudorca crassidens): Hawaiian Islands stock complex - Main Hawaiian Islands Insular, Northwestern Hawaiian Islands,and Hawai'i pelagic stocks. https://media.fisheries.noaa.gov/ dam-migration/po2012whfk-isl_508.pdf

NOAA. (2016). Federal Register: protective regulations for Hawaiian spinner dolphins under the Marine Mammal Protection Act. https://www.federalregister.gov/documents/2016/08/24/201620324/protective-regulations-for-hawaiian-spinner-dolphins-underthe-marine-mammal-protection-act

NOAA. (2017a). Common Bottlenose Dolphin (Tursiops truncatus truncatus): Hawaiian Islands Stock Complex- Kauai /Niiahu, Oahu, 4-island, Hawai'i 
Island, Hawai'i pelagic. https://media.fisheries.noaa.gov/dam-migration/ pacific-2017-common_bottlenose_dolphin-hawaiian_islands-508.pdf

NOAA. (2017b). NOAA tides \& currents. https://www.tidesandcurrents. noaa.gov/

NOAA. (2017c). Pantropical spotted dolphin (Stenella attenuata attenuata): Hawaiian Islands stock complex - Oahu, 4-Islands, Hawai'i Island, and Hawai'i pelagic stocks. https://media.fisheries.noaa.gov/dam-migration/ pacific-2017-pantropical_spotted_dolphin-hawaiian_islands-508.pdf

NOAA. (2018). Spinner dolphin (Stenella longirostris longirostris): Hawaiian Islands stock complex- Hawai'i Island, Oahu/4-islands, Kauai/Niihau, Pearl \& Hermes Reef, Midway Atoll/Kure, Hawai'i pelagic. https://media.fisheries. noaa.gov/dam-migration/hi_spinner_dolphins_final_2018.pdf

Olson, D. M., \& Dinerstein, E. (2002). The global 200: Priority ecoregions for global conservation. Annals of the Missouri Botanical Garden, 89(2), 199224. https://doi.org/10.2307/3298564

Oppel, S., Meirinho, A., Ramírez, I., Gardner, B., O'Connell, A. F., Miller, P. I., \& Louzao, M. (2012). Comparison of five modelling techniques to predict the spatial distribution and abundance of seabirds. Biological Conservation, 156, 94-104. https://doi.org/10.1016/j.biocon.2011.11.013

Pearce, J. L., \& Boyce, M. S. (2006). Modelling distribution and abundance with presence-only data. Journal of Applied Ecology, 43, 405-412. https: //doi.org/10.1111/j.1365-2664.2005.01112.x

Phillips, S. J. (2009). Sample selection bias and presence-only distribution models : Implications for background and pseudo-absence data Reference Sample selection bias and presence-only distribution models: Implications for background and pseudo-absence data. Ecological Applications, 19(1), 181-197. https://doi.org/10.1890/07-2153.1.

Phillips, S. J., \& Elith, J. (2010). POC plots: Calibrating species distribution models with presence-only data. Ecology, 91(8), 2476-2484. https://doi. org/10.1890/09-0760.1.

Pirotta, E., Booth, C. G., Costa, D. P., Fleishman, E., Kraus, S. D., Lusseau, D., Moretti, D., New, L. F., Schick, R. S., Schwarz, L. K., Simmons, S. E., Thomas, L., Tyack, P. L., Weise, M. J., Wells, R. S., \& Harwood, J.. (2018). Understanding the population consequences of disturbance. Ecology and Evolution, 8(19), 9934-9946. https://doi.org/10.1002/ece3.4458

Raithel, J. D., Kauffman, M. J., \& Pletscher, D. H. (2007). Impact of spatial and temporal variation in calf survival on the growth of elk population. Journal of Wildlife Management, 71(3), 795-803. https://doi.org/10.2193/ 2005-608

Rousset, F., \& Ferdy, J. (2014). Testing environmental and genetic effects in the presence of spatial autocorrelation. Ecography, 37(8), 781-790. https://doi.org/10.1111/ecog.00566

Royle, J. A., Chandler, R. B., Yackulic, C., \& Nichols, J. D. (2012). Likelihood analysis of species occurrence probability from presence-only data for modelling species distributions. Methods in Ecology and Evolution, 3(3), 545-554. https://doi.org/10.1111/j.2041-210X.2011.00182.x

Silber, G. K., Adams, J. D., Asaro, M. J., Cole, T. V., Moore, K. S., Ward-Geiger, L. I., \& Zoodsma, B. J., (2015). The right whale mandatory ship reporting system: A retrospective. PeerJ, 3, e866. https://doi.org/10.7717/peerj. 866

State of Hawai'i Office of Planning. (2017). Office of Planning GIS Data. State of Hawai'i Office of Planning.

Stack, S. H., Olson, G. L., Neamtu, V., Machernis, A. F., Baird, R. W., \& Currie, J. J. (2020). Identifying spinner dolphin Stenella longirostris longirostris movement and behavioral patterns to inform conservation strategies in
Maui Nui, Hawai' i. Marine Ecology Progress Series, 644, 187-197. https: //doi.org/10.3354/meps13347

Sundblad, G., Bergström, U., \& Sandström, A. (2011). Ecological coherence of marine protected area networks: A spatial assessment using species distribution models. Journal of Applied Ecology, 48(1), 112-120. https:// doi.org/10.1111/j.1365-2664.2010.01892.x

Syfert, M. M., Smith, M. J., \& Coomes, D. A. (2013). The effects of sampling bias and model complexity on the predictive performance of MaxEnt species distribution models. Plos One, 8(2),. https://doi.org/10.1371/ journal.pone.0055158

Thorson, J. T., Jannot, J., \& Somers, K. (2017). Using spatio-temporal models of population growth and movement to monitor overlap between human impacts and fish populations. Journal of Applied Ecology, 54(2), 577-587. https://doi.org/10.1111/1365-2664.12664

Tyne, J. A., Johnston, D. W., Rankin, R., Loneragan, N. R., \& Bejder, L. (2015). The importance of spinner dolphin (Stenella longirostris) resting habitat: Implications for management. Journal of Applied Ecology, 52(3), 621-630. https://doi.org/10.1111/1365-2664.12434

Van Cise, A., Baird, R., Harnish, A., Currie, J., Stack, S., Cullins, T., \& Gorgone, A. (2021). Mark-recapture estimates suggest declines in abundance of common bottlenose dolphin stocks in the main Hawaiian Islands. Endangered Species Research. In press. https://doi.org/10.3354/esr01117

van Strien, A. J., van Swaay, C. A. M., \& Termaat, T. (2013). Opportunistic citizen science data of animal species produce reliable estimates of distribution trends if analysed with occupancy models. Journal of Applied Ecology, 50(6), 1450-1458. https://doi.org/10.1111/1365-2664.12158

Wickham, H., Chang, W., \& Henry, L. (2018). ggplot2: Elegant Graphics for Data Analysis. Springer-Verlag New York. ISBN 978-3-319-24277-4, https:// ggplot2.tidyverse.org.

Williams, R., Hedley, S. L., \& Hammond, P. S. (2006). Modeling distribution and abundance of Antarctic baleen whales using ships of opportunity. Ecology and Society, 11(1), 1. https://doi.org/10.5751/ES-01534-110101

zu Ermgassen, P. S. E., Grabowski, J. H., Gair, J. R., \& Powers, S. P. (2016). Quantifying fish and mobile invertebrate production from a threatened nursery habitat. Journal of Applied Ecology, 53(2), 596-606. https://doi. org/10.1111/1365-2664.12576

\section{SUPPORTING INFORMATION}

Additional supporting information may be found online in the Supporting Information section at the end of the article.

How to cite this article: Self H, Stack SH, Currie JJ, \& Lusseau D (2021). Tourism informing conservation: the distribution of four dolphin species varies with calf presence and increases their vulnerability to vessel traffic in the four-island region of Maui, Hawai' i. Ecol Solut Evidence, 2:, e12065. https://doi.org/10.1002/2688-8319.12065 